\title{
ESTUDOS SOBRE A NUTRIÇÃO MINERAL DO SORGO GRANIFERO. VI. ABSORÇÃO DE FOSFATO POR RAIZES DESTACADAS DE PLANTAS DE TRES VARIEDADES COMERCIAIS *
}

\author{
E. Malavolta ** \\ F.M. Freire, J.C. Casagrande, M.V. \\ Carretero \& R. Stolf \\ J.F. Pedras, M.E.S.P. Dematté, R. \\ A. Pitelli \& W. Politano***
}

\section{RESUMO}

Foi estudada a absorção de fosfato marcado com ${ }^{32} \mathrm{P}$ por raizes destacadas de três variedades de sorgo granífero. A influência do tempo, concentração iônica externa, $\mathrm{pH}$, aeração, venenos respiratórios e desacopladores de fosforilação oxidativa foi considerada; o estudo da cinéstica da absorção mostrou diferenças entre as variedades nos parâmetros michaelianos.

\section{INTRODUÇÃO}

$\mathrm{O}$ iônio $\mathrm{H}_{2} \mathrm{PO}_{4}^{-}$é a forma principal na qual o fósforo (P) é absorvido por ser a predominante nas condições de $\mathrm{pH}$ em que vivem as plantas. Diferentemente do $\mathrm{N}-\mathrm{NO}_{3}{ }^{-}$e $\mathrm{S}_{-} \mathrm{SO}_{4}{ }^{2-}$, o fósforo não sofre redução no interior da planta (EPSTEIN, 1975). fusão.

Entra em contato com a raiz principalmente pelo processo de di-

Os compostos de fósforo são cruciais para inúmeros processos metabólicos (MALAVOLTA, 1976). Esteres de carbohidratos, nucleotídeos, fosfolipídeos, apresentam-no em sua constituição. Participa dos processos de armazenamento e transferência de energia.

* Entregue para publicação em 12-12-1977.

Com ajuda do BNDE (FUNTEC 293), FAPESP e CNEN.

* Departamento de Química e CENA, E.S.A. "Luiz de Queiroz", USP.

** Estudantes pós graduados de Solos \& Nutrição de Plantas. 
O presente trabalho tem por objetivo estudar o efeito da concentração externo, tempo, pH, temperatura, aeração e venenos respiratórios (fluoreto, cianeto e 2,4-DNP).

\section{REVISÃO DE LITERATURA}

HAGEN \& HOPKINS (1955) estudaram a cinética de absorção de fosfato por raízes de cevada. Observaram que a absorção é essencialmente irreversíveis e envolve dois mecanismos independentes.

Os dados de absorção defosfato por raízes destacadas de trevo subterrâneo, originalmente interpretados por NISSEN (1973), para o duplo mecanismo, refletem a existência de dois sítios de carregadores com afinidades levemente diferentes.

Segundo PHILLIPS et alii (1971), a cinética de absorção de fosfato por raízes de milho é semelhante àquela para raízes de cevada, nas quais dois mecanismos independentes de absorção foram observados.

A absorção de fósforo em diferentes concentrações de fosfato (1 x $10^{-6}$ a $1 \times 10^{-3} \mathrm{M}$ ), foi estudado por NOGGLE \& FRIED (1960) . A quantidade absorvida dividida pela concentração de $\mathrm{P}$ na solução mostrou uma relação curvilinea. Segundo esses autores esta relação curvilinea é semelhante ao sistema descrito por HOFSTEE (1952), no qual duas enzimas (carregadores) atuam simultaneamente e independentemente no mesmo substrato (P). Aparentemente, observaram que todas as três espécies estudadas (painço, cevada e alfafa) absorvem fosfato por dois processos independentes. Segundo os autores, os resultados obtidos são concordantes com aqueles obtidos por HAGEN \& HOPKINS (1955).

PHILLIPS et alii (1971) estudaram a absorção de fósforo em ' função do tempo, usando solução 2,5 x $10^{-3} \mathrm{M}$ de fosfato, a pH 5,0. Foi observada a existência de um equilíbrio dinâmico para a taxa linear de absorção num período de 10 horas.

NOGGLE \& FRIED (1960), estudaram a absorção de fósforo de soluções $1 \times 10^{-6}$ e $5 \times 10^{-4} M$ de $P$ medidas a intervalos de 90 segundos, num período de 10 minutos. Observaram que a quantidade de $\mathbf{P}$ absorvida em função do tempo apresentou uma linha reta, indicando que a absorção encontra em equilíbrio neste intervalo de tempo.

O conteúdo de $P$ em batata, de acordo com NIELSEN et alii (1961), sem adição de $\mathbf{P}$ durante o crescimento, aumentou com o aumento de temperatura, enquanto que, em milho, a concentração de fósforo não variou com o aumento de temperatura. Ketcheson ((1957), citado por NIELSEN, observou que o teor de $\mathrm{P}$ em milho aumentou quando a temperatura variou de 55 a $67^{\circ} \mathrm{C}$. 
A porcentagem de $P$ na parte aérea e sistema radicular foi muito pouco influenciada pela temperatura radicular, mas dependeu em grande parte do nível de P na solução nutritiva (KNOLL et alii, 1964). Citam ainda que o conteúdo de $\mathrm{P}$ no tecido não governa $\mathrm{o}$ crescimento das plantas. Plantas crescendo a baixa temperatura radicular $\left(15^{\circ} \mathrm{C}\right)$ e a alto nível de $\mathrm{P}((15 \mathrm{ppm})$ apresentavam duas vezes mais $P$ no tecido da parte aérea que plantas desenvolvidas a alta temperatura radicular $\left(25^{\circ} \mathrm{C}\right)$ e a baixo nível de $P(5 \mathrm{ppm})$ na solução nutritiva. A produção de matéria seca das plantas desenvolvidas a baixa temperatura radicular era aproximadamente $1 / 5$ daquelas crescidas a alta temperatura radicular. Para esses autores, o reduzido crescimento a baixa temperatura radicular não foi um efeito indireto, mas um efeito direto da temperatura sobre o metabolismo das células.

HUMBERT (1968) cita que para cana-de-açúcar a razão de absorção e translocação de ${ }^{32} \mathbf{P}$ foi duas ou três vezes mais rápida a 22 que a $16^{\circ} \mathrm{C}$.

LINGLE \& DAVIS (1959), cultivaram "seedlings" de tomate a diferentes temperaturas radiculares $\left(9\right.$ a $\left.18^{\circ} \mathrm{C}\right)$ e diferentes níveis de fósforo. Observaram que a concentração de nutrientes no tecido aumento da temperatura radicular, exceto aquelas de $\mathrm{Ca}$ e $\mathrm{Mg}$. Estes autores apresentam quatro possíveis explicações para o aumento da absorção em função do aumento da temperatura:

1. Aumento da solubilidade de nutrientes no solo

2. Aumento da atividade respiratória

3. Maior desenvolvimento do sistema radicular

4. Maior absorção de água .

A absorção de $P$ marcado, nas concentrações de $1 \times 10^{-6}$ a $3 \times$ $10^{-5} \mathrm{M}$, por raízes destacadas de plantas jovens de trigo, não dependeu do pH na faixa de 5,0 a 7,0 (BUTLER, 1953).

Observações experimentais indicam que o pH, num contexto ecológico, pouco influi na absorção iônica, já que as plantas vegetam numa faixa de pH que varia de 4,0 a 8,0 (MALAVOLTA, 1970).

HOPKINS (1956) observou que a velocidade de absorção de fosfato é independente da pressão parcial de oxigênio, na faixa de 3 a $100 \%$ de $\mathrm{O}_{2}$. Verificou também a existência de uma relação hiperbólica entre a taxa de absorção de fosfato e a tensão de oxigênio, entre os limites de 0 (zero) a $0,3 \%$ de $\mathrm{O}_{2}$. A taxa máxima de absorção ocorreu na concentração de $3,0 \%$ de $\mathrm{O}_{2}$, enquanto que a $0,3 \%$ de $\mathrm{O}_{2}$ a taxa máxima de absorção reduziu'se a metade. 
Segundo MALAVOLTA (1970), não há dúvida de que a acumulação é processo aeróbico, visto que raízes destacadas colocadas em solução salina, na qual foi borbulhado $\mathrm{N}_{2}$, praticamente não realizam absorção.

O fluoreto relatado por MC MULTY \& LORDES (1960) é considerado como um inibidor de respiração, embora em baixas concentrações possa estimulá-la.

BUTLER (1953), verificou que $\mathrm{KCN} 10^{3} \mathrm{M}, \mathrm{pH}$ 6,5 e em ausência de aeração, provocou forte inibição na absorção de ${ }^{32} \mathrm{P}$ enquanto que o P total permaneceu constante. Isto sugere que, enquanto o processo acumulatório e assimilatório são fortemente inibidos pelo cianeto, o transporte de fosfato não é apreciavelmente afetada.

O 2,4-dinitrofenol inibiu competitivamente a absorção de $\mathrm{H}_{2} \mathrm{PO}_{4}$ - e $\mathrm{HPO}_{4}{ }^{2-}$, quando presente na concentração de $3,10^{-6} \mathrm{M}$ e $\mathrm{pH} 4,0$ (HOPKINS, 1956).

De acordo com LOUGHMAN \& RUSSEL (1957) trabalhando com plantas jovens de cevada, a concentração de DNP $5 \times 10^{-6} \mathrm{M}$ não afetou a retenção metabólica de fosfato. Entretanto, concentração de 5 $\times 10^{-5} \mathrm{M}$ reduziu a absorção em torno de $50 \%$.

Segundo JAMES (1953) citando vários autores baixas concentrações de dinitrofenol estimularam marcadamente a absorção de $\mathrm{O}_{2}$ por discos de cenoura, folhas e raízes de trigo. Altas concentrações, $10^{-5} \mathrm{e}$ $10 \mathrm{~m}$ podem acelerar a respiração anaeróbica. Há forte inibição da fosforilação e formação de fosfatos ricos em energia em concentraçõas nas quais houve estímulo à absorção de $\mathrm{O}_{2}$.

\section{MATERIAL E MÉTODOS}

\subsection{Variedades usadas}

As variedades de sorgo granífero (Sorghum bicolor Moench) utiliutilizada foram: Tey, Contibrasil 102 e Dekalb.

3.2. Absorção de fósforo em funçã்o do tempo

3.2.1. Obtenção das raízes

As sementes foram colocadas para germinar em substrato de vermiculita em bandeja plástica, mantida constantemente umedecida com solução de $\mathrm{CaSO}_{4} 1^{-4} \mathbf{M}$. Quando as plantas atingiram 2 a $3 \mathrm{~cm}$ de altura, foram transplantadas para solução nutritiva de HOAGLAND \& ARNON (1950) $n .^{\circ} 1$, diluída a $1 / 5$ onde permaneceram por 2 a 3 semanas: Até a utilização das plantas foi mantido um sistema contínuo de aeração sendo o volume de solução nutritiva completado com água destilada, à medida da necessidade. Por ocasião da realização do experimento, as raízes foram lavadas em água corrente e repassadas em água destilada.: O mesmo procedimento foi seguido em todos os ensaios. 
3.2.2. Soluções utilizadas

- $\mathrm{NaH}_{2} \mathrm{PO}_{4}-10^{-4} \mathrm{M}$

- $\mathrm{MgSO}_{4}-2 \times 10^{-4} \mathrm{M}$

- $\mathrm{NaH}_{2}{ }^{32} \mathrm{PO}_{4}$ - isenta de carregador, atividade $=147000$ c.p.m./ml., na hora da contagem

3.2.3. Delineamento experimental

$\mathrm{O}$ delineamento experimental usado foi o inteiramente casualizado num esquema fatorial, com 3 repetições

3.2.4. Tratamentos

A absorção por raízes destacadas das 3 variedades foi estudada em função dos seguintes tempos: $5,15,45$ e 240 minutos.

3.2.5. Condução do experimento

As raízes destacadas após a lavagem, foram colocadas nos respectivos frascos constituintes dos tratamentos. Cada frasco havia recebido $100 \mathrm{ml}$ de solução de $\mathrm{NaH}_{2} \mathrm{PO}_{4} 10^{-4} \mathrm{M}, 1 \mathrm{ml}$ de solução de $\mathrm{MgSO}_{4} 2 \times$ $10^{-4} \mathrm{M}$ e $1 \mathrm{ml}$ desolução de $\mathrm{NaH}_{2}{ }^{32} \mathrm{PO}_{4}$. Foi mantido um sistema contínuo de aeração. Completado os tempos de absorção as soluções foram retiradas por decantação, os volumes dos frascos completados com água destilada. Em seguida as raízes foram lavadas por 3 vezes com $100 \mathrm{ml}$ de água destilada. Após as lavagens, as raízes foram levadas para estufa a $70^{\circ} \mathrm{C}$. Depois de secas e pesadas, transferiu-se para as cápsulas de vidro de $5 \mathrm{ml}$ de capacidade e de $2 \mathrm{~cm}$, determinando-se a atividade com contador Geiger-Muller de janela de mica ligado a escalímetro.

3.3. Absorção de fósforo em função da concentração externa

3.3.1. Soluções utilizadas

As soluções utilizadas foram

$\mathrm{NaH}_{2} \mathrm{PO}_{4} \quad-0,01 \mathrm{~m}$ moles $/ 1$

$0,05 \mathrm{~m}$ moles $/ 1$

$0,10 \mathrm{~m} \mathrm{moles} / 1$

$0,20 \mathrm{~m} \mathrm{moles} / 1$ $1,00 \mathrm{~m} \mathrm{moles} / 1$

$\mathrm{NaH}_{2}{ }^{32} \mathrm{PO}_{4}$ - isenta de carregador, atividade $=71048$ $\begin{array}{lll}\mathrm{MgSO}_{4} & 10^{-2} \mathrm{M}\end{array}$

3.3.2. Delineamento experimental

$\mathrm{cpm} / \mathrm{ml}$

O delineamento experimental usado foi o inteiramente casualizado num esquema fatorial, com 3 repetições.

\subsubsection{Tratamentos}

Foi estudada a absorção em função de 5 concentrações externas de $\mathrm{NaH}_{2} \mathrm{PO}_{4}(0,01 \mathrm{~m}$ moles $/ 1 ; 0,05 \mathrm{~m}$ moles $/ 1 ; 0,10 \mathrm{~m}$ moles $/ 1 ; 0,20 \mathrm{~m}$ moles $/ 1$ e $1,00 \mathrm{~m}$ moles $/ 1$ ). 
3.3.4. Condução do experimento

De acordo com o anterior. Duração: 2 horas

3.4. Efeito da temperatura e $\mathrm{pH}$ na absorção de fósforo

3.4.1. Soluções utilizadas

$\mathrm{Na} \mathrm{H}_{2} \mathrm{PO}_{4} \quad 10^{-4} \mathrm{M}$

$\mathrm{MgSO}_{4} 2 \times 10^{-2} \mathrm{M}$

$\mathrm{NaH}_{2}{ }^{32} \mathrm{PO}_{4}$ - isenta de carregador, $\mathrm{A}=22199$ c.p.m./ $\mathrm{ml}$ na hora da contagem

As soluções com pH3 e 6,0 foram ajustadas potenciometricamente usando $\mathrm{HCl} 0,1 \mathrm{~N}$ e $\mathrm{NaOH} 0,1 \mathrm{~N}$, respectivamente.

3.4.2. Delineamento experimental

O delineamento experimental utilizado para os ensaios de efeito de temperatura e pH na absorção de fósforo foi o inteiramente casualidado num esquema fatorial com 4 repetições.

\subsubsection{Tratamentos}

- Efeito da temperatura na absorção de fósforo

Foram estudados a absorção por raízes destacadas de 3 variedades de sorgo citadas em 3.1. em duas temperaturas $\left(0^{\circ} \mathrm{C}\right.$ e $\left.30^{\circ} \mathrm{C}\right)$.

- Efeitodo pH na absorção de fósforo

Foram testadas a absorção por raízes destacadas de 3 variedades de sorgo citada em 3.1. em dois valores de $\mathrm{pH}(3,0$ e 6,0) .

\subsubsection{Condução do experimento}

Os volumes das soluções utilizadas por frasco, tanto pa aro efeito de temperatura quanto de $\mathrm{pH}$ na absorção de fósforo, foram:

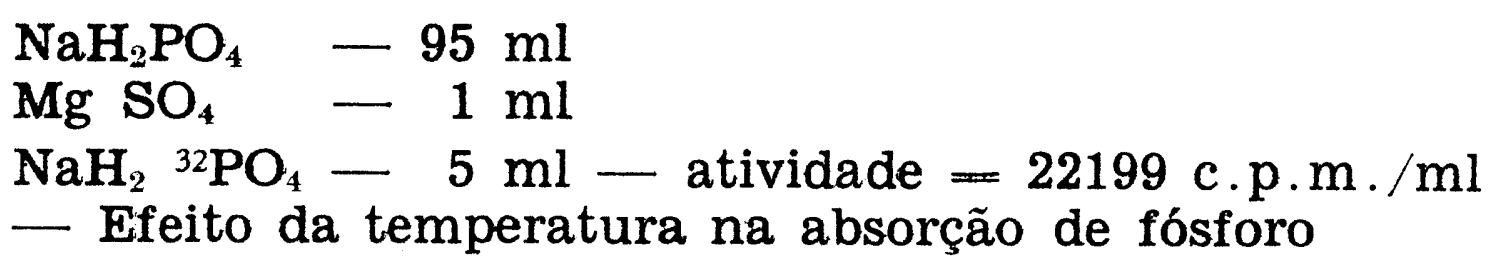

As raízes destacadas foram colocadas nos frascos contendo as soluções onde então foram variadas as temperaturas. Um sistema de aeração foi mantida. Após 2 horas o ensaio foi terminado.

- Efeito de pH na absorção de fósforo

A metodologia de condução do ensaio de efeito de pH é semelhante àquela utilizada no ensaio de efeito da temperatura; ao invés de se estudar 2 níveis de temperaturas, estudou-se a absorção a 2 valores de $\mathrm{pH}(3,0$ e 6,0$)$. foro

3.5. Efeito do arejamento e dos inibidores na absorção de fós- 
3.5.1. Soluções utilizadas

$\mathrm{NaH}_{2} \mathrm{PO}_{4} \quad 10^{-4} \mathrm{M}$

$\mathrm{MgSO}_{4} 2 \times 10^{-2} \mathrm{M}$

$\mathrm{NaH}_{2}{ }^{32} \mathrm{PO}_{4}$ - isenta de carergador, $\mathrm{A}=5186$ c.p.m. $/ \mathrm{ml}$

$\mathrm{KF} 0,04 \mathrm{M}$

$\mathrm{KCN} 0,5 \mathrm{M}$

2,4 DNP $10^{-3} \mathrm{M}$

3.5.2. Delineamento experimental

O delineamento experimental utilizado foi o inteiramente casualizado num esquema fatorial. Utilizou-se 4 repetições.

\subsubsection{Tratamentos}

Estudou-se o efeito do arejamento, ausência de arejamento, CN-, F- e 2,4 DNP na absorção de fósforo por raízes destacadas das 3 variedades. Todos os tratamentos com excessão da ausência de arejamento, receberam aeração.

3.5.4. Condução do experimento

Todos os frascos receberam $95 \mathrm{ml}$ de $\mathrm{NaH}_{2} \mathrm{PO}_{4}$. Os tratamentos com $\mathrm{CN}^{-}$e 2,4 DNP receberam $1 \mathrm{ml}$ de $\mathrm{KCN} 0,5 \mathrm{M}$, e $1 \mathrm{ml}$ de 2,4 DNP $10^{-3} \mathrm{M}$, respectivamente. Especificamente para o $\mathrm{F}$, houve um pré tratamento das raízes, deixando-as mergulhadas em $100 \mathrm{ml}$ de $\mathrm{KF}$ $0,04 \mathrm{M}$ por 2 horas.

Após 2 horas as soluções foram decantadas. Seguiram lavagens das raízes, secamento e contagem da atividade conforme metodologia citada.

\section{RESULTADOS E DISCUSSÃO}

4.1. Absorção de fósforo em função do tempo

A Tabela 1 apresenta os valores médios de absorção de $\mathbf{P}$ em função do tempo de contacto da solução externa com raízes destacadas de três variedades de sorgo.

TABELA 1 - Absorção de $\mathrm{P}$ por raizes destacadas de três variedades de sorgo em função do tempo de contacto com a solução externa (u moles $\mathrm{P} / \mathrm{g}$ matéria seca)

\begin{tabular}{lllrl}
\hline & \multicolumn{4}{c}{ tempo (min.) } \\
Variedade & 5 & 15 & 45 & 240 \\
\hline CBr & 2,55 & 7,26 & 13,01 & 41,92 \\
DeKalb & 1,33 & 1,87 & 4,23 & 38,72 \\
Tey & 1,25 & 3,02 & 6,97 & 22,73 \\
Média & 1.71 & 4,05 & 8,07 & $34,4 \epsilon$ \\
\hline
\end{tabular}




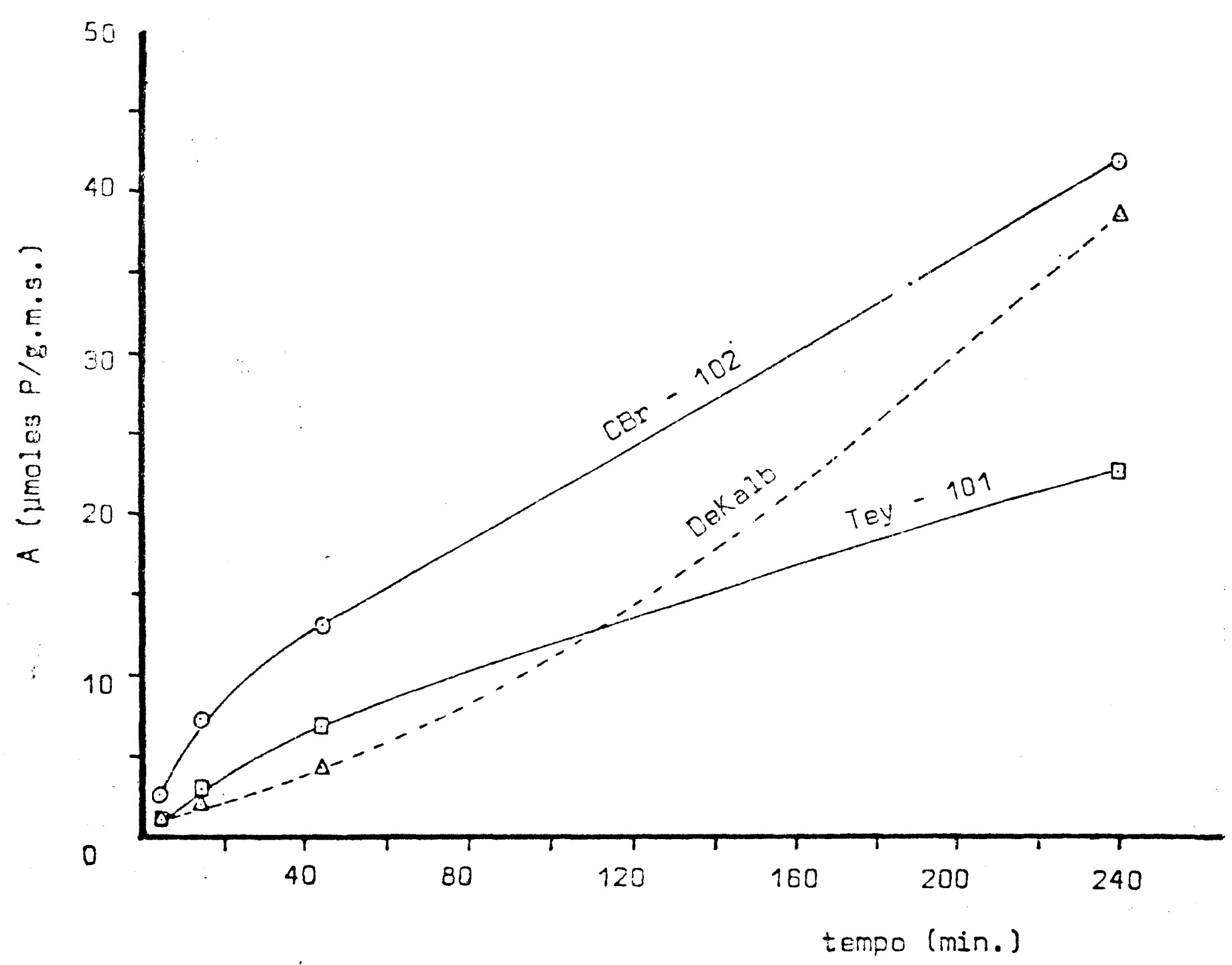

Figura 1 - Absorção de $\mathrm{P}$ por raízes destacadas de três variedades de sorgo em função do tempo de contato com a solução externa $(0,1 \mu$ moles $\mathrm{P} / \mathrm{ml})$.

Na Fig. 1 tem-se a representação gráfica do comportamento das três variedades e na Fig. 2 a média das três variedades em função do tempo.

Como as variedades se comportam de maneiras diferentes conforme revelou a análise de variância, procurou-se determinar a velocidade relativa de absorção das mesmas.

4.1.1. Cálculo da velocidade relativa de absorção entre as variedades

Estabeleceu-se que a equação (1) representa bem o fenômeno biológico ocorido nas condições impostas pelo experimento:

$$
A=A_{\max }\left(1-\mathrm{e}^{-k t}\right) \ldots \ldots \ldots \ldots \ldots \text { (1) }
$$

onde $\mathrm{A}=$ absorção de fósforo, ou seja, massa de fósforo absorvido por grama de matéria seca (u moles - P/g.m.s.)

$\mathrm{A}_{\max }=$ absorção máxima de fósforo

$\mathrm{t}=$ tempo (min.) 


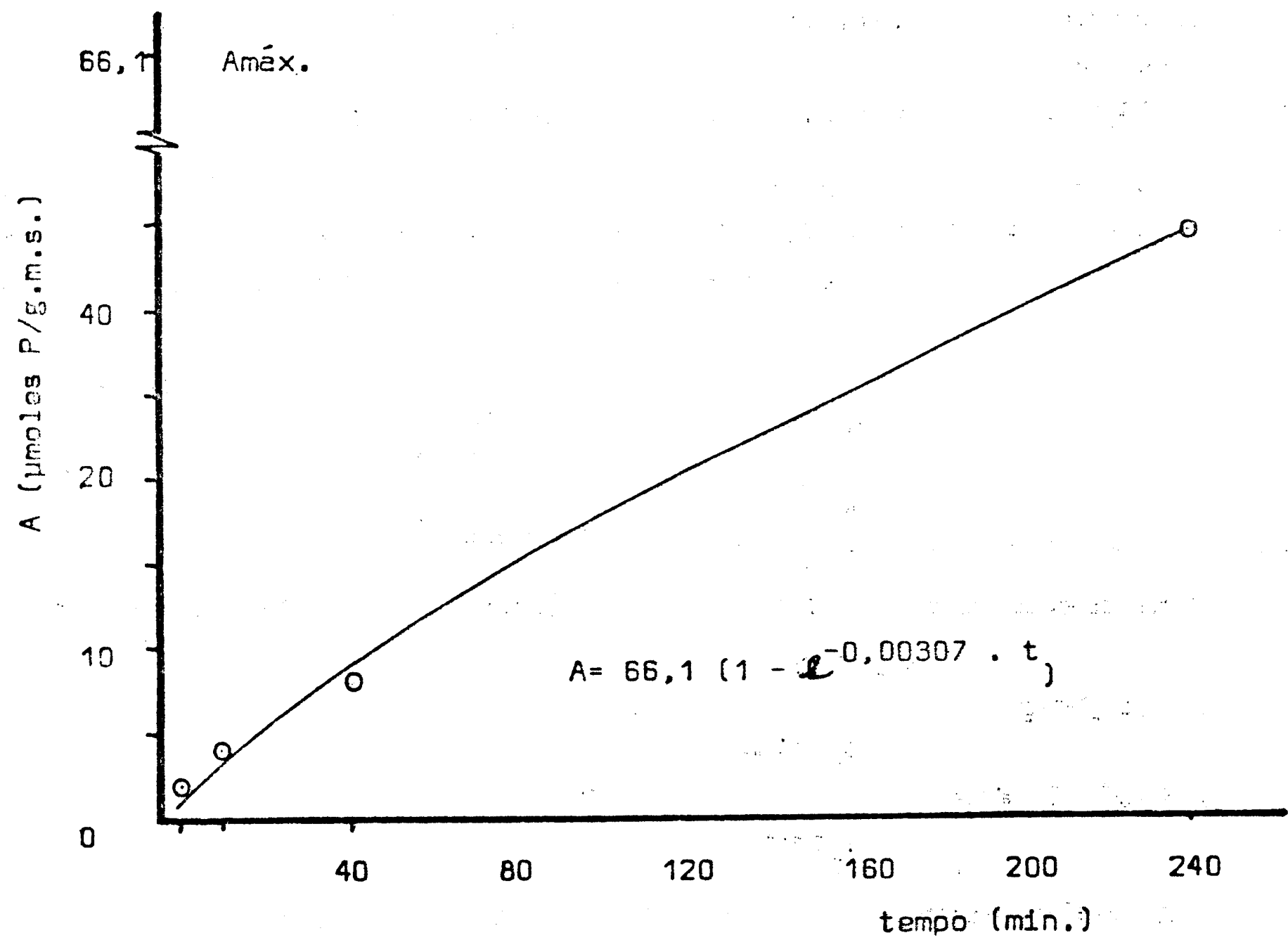

Figura 2 - Absorção de $\mathrm{P}$ por raízes destacadas de sorgo. Média das três variedades em função do tempo. Concentração da solução externa: $0,1 \mu$ moles $\mathrm{P} / \mathrm{ml}$.

$\mathrm{K}=$ constante relacionada com a velocidade de absorção $\left(\min .^{-1}\right)$

$\mathrm{e}=2,718 \ldots$ (base do lagaritimo natural).

A expressão (1) pode ser obtida integrando-se a equação diferencial de Mitscherlich.

A derivada da expressão (1) em relação ao tempo é a velocidade de absorção:

$$
\begin{aligned}
& \mathrm{v}=\frac{\mathrm{dA}}{\mathrm{dt}}=\mathrm{K}{\underset{\max }{(\mathrm{A}}-\mathrm{A})}^{0,00179} . \\
& \mathrm{k}=\frac{\mathrm{V}}{\mathrm{V}_{1}}=\frac{\mathrm{K}_{1}}{\mathrm{~K}_{2}}
\end{aligned}
$$

Se duas variedades ( 1 e 2 por ex.) se apresentam com a mesma absorção máxima (Amax) a velocidade relativa de absorção é dada pela relação entre as constantes: 
Inicialmente ajustou-se a expressão (1) para a média das três variedades, obtendo-se:

$A_{\max }=66,1$ umoles $\mathrm{p} / \mathrm{g} \cdot \mathrm{m} . \mathrm{s}$. e $\mathrm{K}=0,00307 \mathrm{~min}^{-1}$

Para se obter os valores médios relativos das velocidades de absorção entre as variedades, estabeleceu'se $\mathrm{A}_{\max }=66,1$ para as três variedades e ajustou-se a expressão (1) para cada uma delas. As equações obtidas foram:

C. Br.

DeKalb

Tey

Média das variedades
$\mathrm{A}=66,1\left(1-\mathrm{e}^{-0,00423 . t}\right)$

$A=66,1\left(1-\mathrm{e}^{-0,00359 . t}\right)$

$A=66,1\left(1-\mathrm{e}^{-0,00179 . t}\right)$

$A=66,1\left(1-e^{-0.00307 . t}\right)$ r $(\mathrm{Y}$ e $\mathrm{y})$

99,8

99,4

99,6

99,96

Tomando-se a variedade Tey como base de comparação tem-se

$$
\begin{aligned}
& \mathrm{v}\left(\mathrm{CBr} / \mathrm{Tey}=\frac{0,00423}{0,00359}=2,36\right. \\
& \mathrm{v}\left(\text { DeKalb } / \text { Tey }=\frac{0,00179}{0,01}\right.
\end{aligned}
$$

Uma outra maneira de se comparar seria utilizar a velocidade média de absorção no intervalo de tempo entre 0 e 240 minutos:

$$
\begin{aligned}
& \text { v }(\mathrm{CBr})=\frac{41,92}{240}=0,17 \text { umoles } / \mathrm{min} / \mathrm{g} \cdot \mathrm{m} \cdot \mathrm{s} \\
& \mathrm{v}\left(\text { DeKalb) }-\frac{38,72}{240}=0,16 \mathrm{umoles} / \mathrm{min} / \mathrm{g} \cdot \mathrm{m} \cdot \mathrm{s} .\right. \\
& \mathrm{v}(\text { Tey })=\frac{22,73}{240}=0,09 \text { umoles } / \mathrm{min} / \mathrm{g} \cdot \mathrm{m} \cdot \mathrm{s} .
\end{aligned}
$$

Portanto,

$\mathrm{v}(\mathrm{CBr} / \mathrm{Tey})=1,8$

$\mathrm{V}(\mathrm{DeKalb} / \mathrm{Tey})=1,7$

Considerando agora a velocidade média de ab sorção no intervalo de 0 a 45 e 45 a 240 minutos tem-se:

$$
0-45 \mathrm{~min}
$$

$45-240 \mathrm{~min}$

$\begin{array}{lll}{ }_{\mathrm{CBr}} & 0,29 \text { umoles } / \mathrm{g} / \mathrm{min} & 0,15 \mathrm{umoles} / \mathrm{P} / \mathrm{g} / \mathrm{min} \\ \text { DeKalb } & 0,09 \text { umoles } / \mathrm{g} / \mathrm{min} & 0,18 \mathrm{umoles} / \mathrm{g} / \mathrm{min} \\ \text { Tey } & 0,15 \text { umoles } / \mathrm{g} / \mathrm{min} & 0,08 \mathrm{umoles} / \mathrm{g} / \mathrm{min}\end{array}$


Verifica-se, através desses resultados, que apenas a variedade DeKalb teve velocidade de absorção de $P$ aumentada no primeiro ( 0 $45 \mathrm{~min}$ ) para o segundo intervalo $(45-240 \mathrm{~min})$ considerado. Esse comportamento é discordante com dados da literatura (NOGLE \& FRIED, 1960 e JACK et alii, 1962). Isto sugere novas pesquisas para melhor entendimento do fenômeno. 
De maneira geral, no intervalo de 0 a 240 minutos, nas condições estabelecidas pelo experimento, a velocidade de absorção das variedades C.Br. - 102 e DeKalb se mostraram cerca de 2 vezes maior que a variedade Tey 101 .

4.2. Variação de absorção de fósforo em função da concentração da solução externa

A Tabela 2 apresenta os valores de absorção de fósforo obtidos com várias concentrações desse elemento na solução externa. Analisando-se a Fig. 3, pode-se observar que o mecanismo duplo de absorção é bem caracterizado apenas pela variedade DeKalb.

TABELA 2 - Variação da absorção de $\mathrm{P}$ em função da concentração externa. Tempo de contato: 2 horas, u moles $\mathrm{P} / \mathrm{g}$ mat. seca.

\begin{tabular}{lccccccc}
\hline Variedades & 0,01 & 0,02 & 0,05 & 0,10 & 0,20 & 0,50 & 1,0 \\
\hline C. Br.-102 & 0,40 & 0,64 & 1,09 & 1,60 & 2,66 & 3,43 & 4,8 \\
DeKalb & 0,98 & 1,43 & 2,05 & 2,16 & 2,30 & 3,36 & 3,99 \\
Tey & 0,49 & 0,74 & 1,09 & 1,77 & 2,70 & 3,83 & 4,39 \\
\hline Média & 0,62 & 0,93 & 1,41 & 1,84 & 2,55 & 3,54 & 4,39 \\
\hline
\end{tabular}

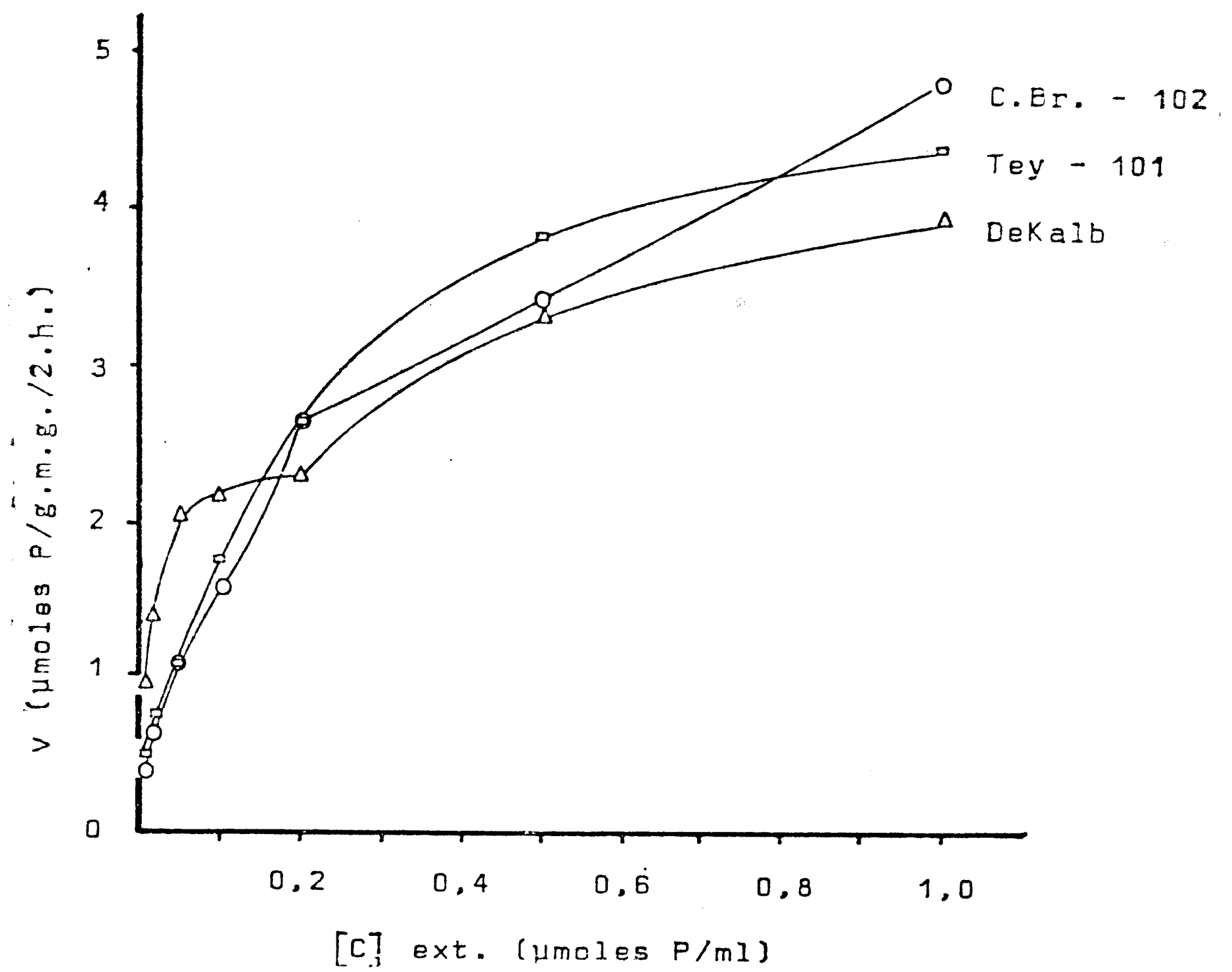

Figura 3 - Absorção de $\mathrm{P}$ por raízes destacadas de três variedades de sorgo em função da concentração da solução externa. Tempo de contacto: 2 horas. 
Parece pouco provável que variedades de uma mesma espécie vegetal apresentam mecanismos duplos de absorção e outras não, para uma grande variação de concentração iônica externa, já que são geneticamente semelhantes. Por essa razão preferiu-se analisar primeiramente a média das variedades, para posteriormente detalhar o fenômeno em termos de diferenças varietais.

A Fig. 4 mostra a variação da absorção média das três variedades. Como se observa, a curva não apresenta pontos de descontinuidade ou de inflexão, indicando que se houver mecanismo duplo de absorção haverá uma interação entre eles na fase de transição, não havendo portanto uma passagem abrupta entre os mesmos.

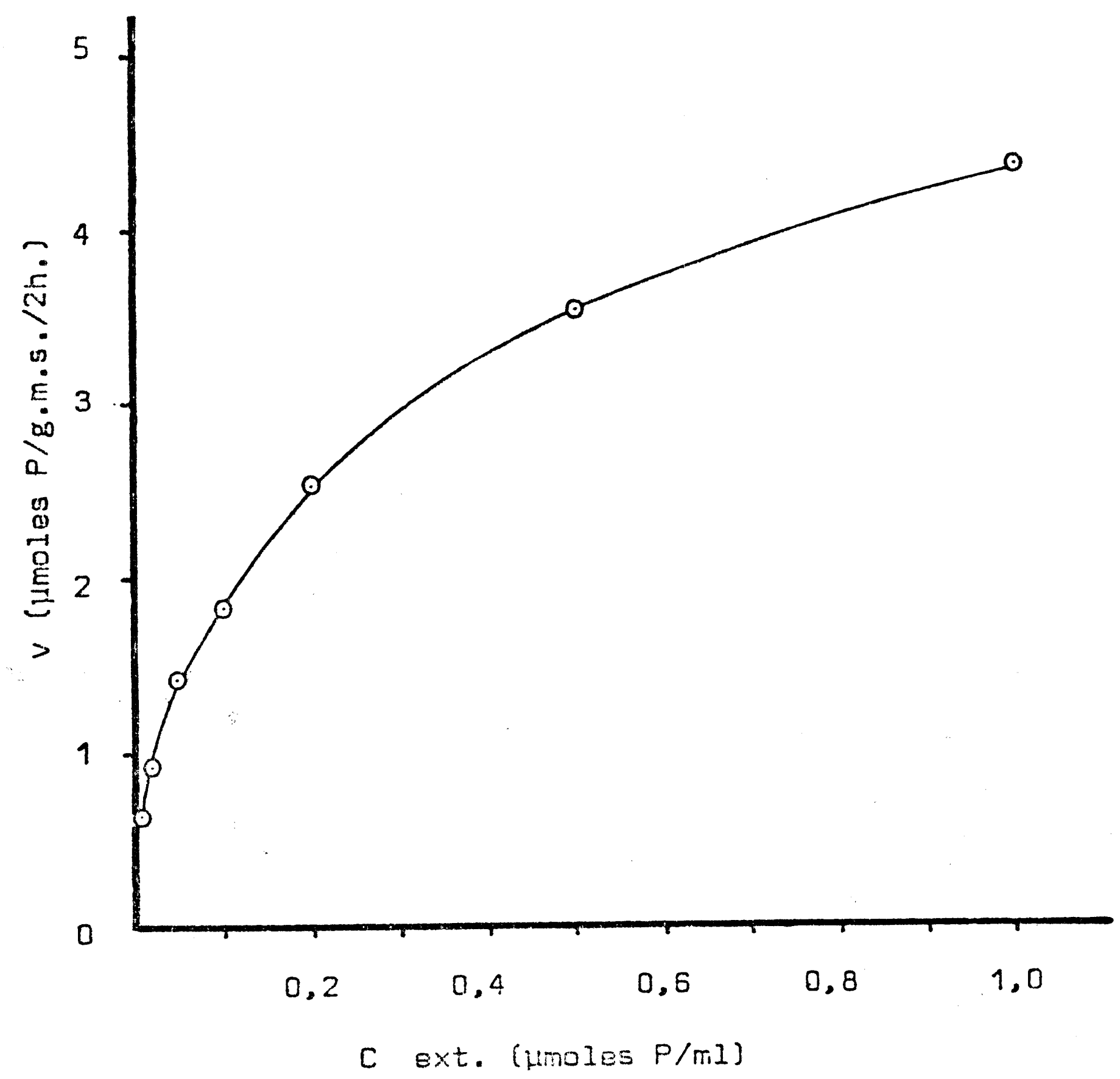

Figura 4 - Absorção de $\mathrm{P}$ por raízes destacadas de sorgo. Média das três variedades. em função da concentração externa. Tempo de contato 2 horas. 
Com efeito, quando se utiliza as transformações de Lineweaver-Burk ou de Hofstee, Fig. 5 e 6 , respectivamente, os dados não se apresentam de maneira linear, como era de se esperar no mecanismo sim-

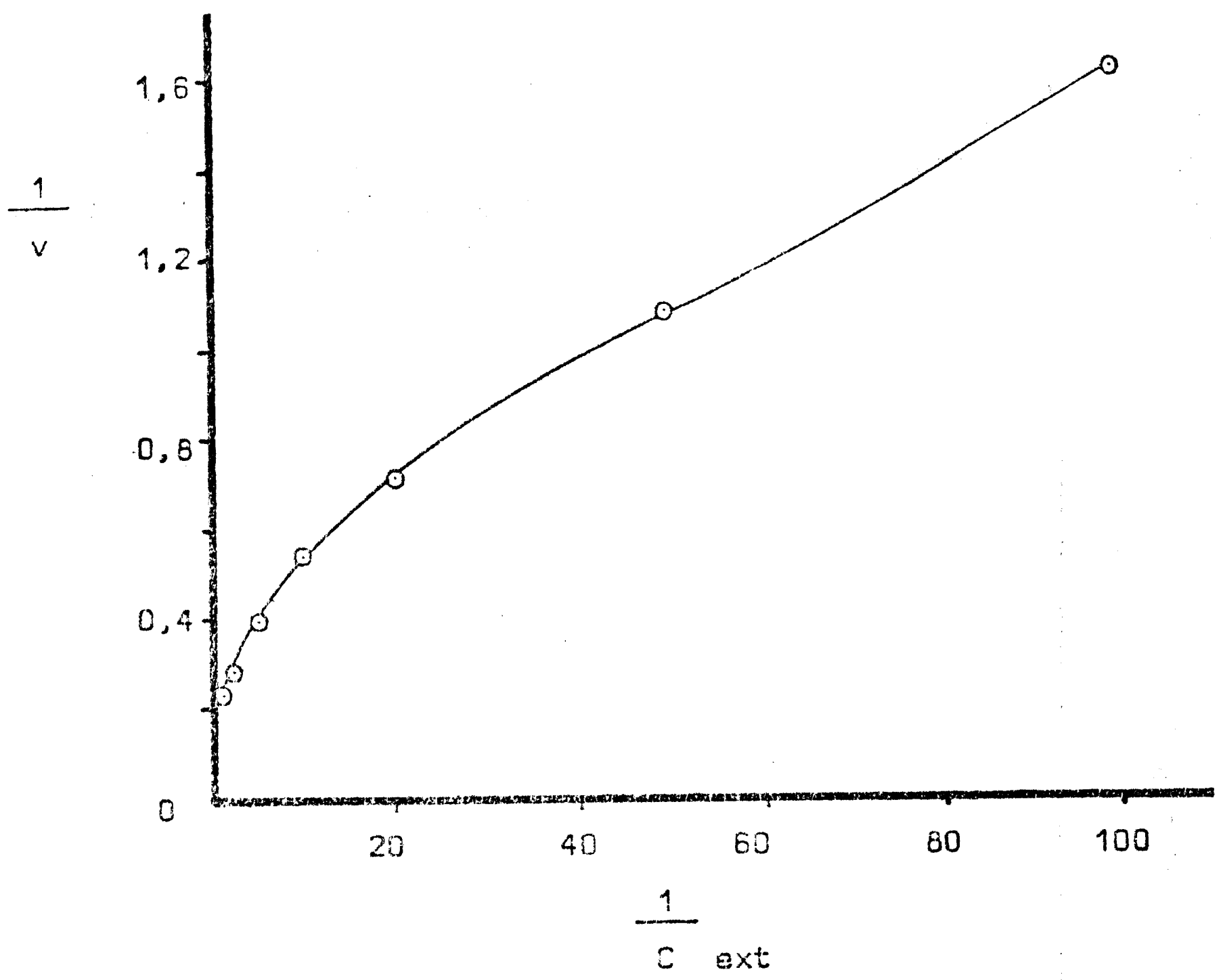

Figura 5 - Transformada de Lineweaver - Burk. Absorção de $\mathrm{P}$ por raízes destacadas de sorgo. Média das três variedades em função da concentração externa. Tempo de contato: 2 horas.

ples de absorção e, nem por duas porções lineares, quando a separação entre os mecanismos é abrupta. Esse comportamento está de acordo com o obtido por HAGEN \& HOPKINS (1955). Segundo esses autores, que trabalharam com raízes destacadas de cevada, os dados na transformada de Hofsteee se apresentam de maneira curvilínea porque duas reações de primeira ordem estão ocorrendo simultaneamente. HOFSTEE (1952) e NOGGLE \& FRIED (1960) mostram como essa curva pode ser decomposta em segmentos lineares utilizando-se métodos gráficos. Em resumo, o processo consiste em traçar duas tangentes à curva obtida pela transformada de Hofstee: uma relativa as baixas concentrações e outra relativa à porção de altas concentrações. Para o intervalo de concentração estabelecido no experimento vê-se clara- 


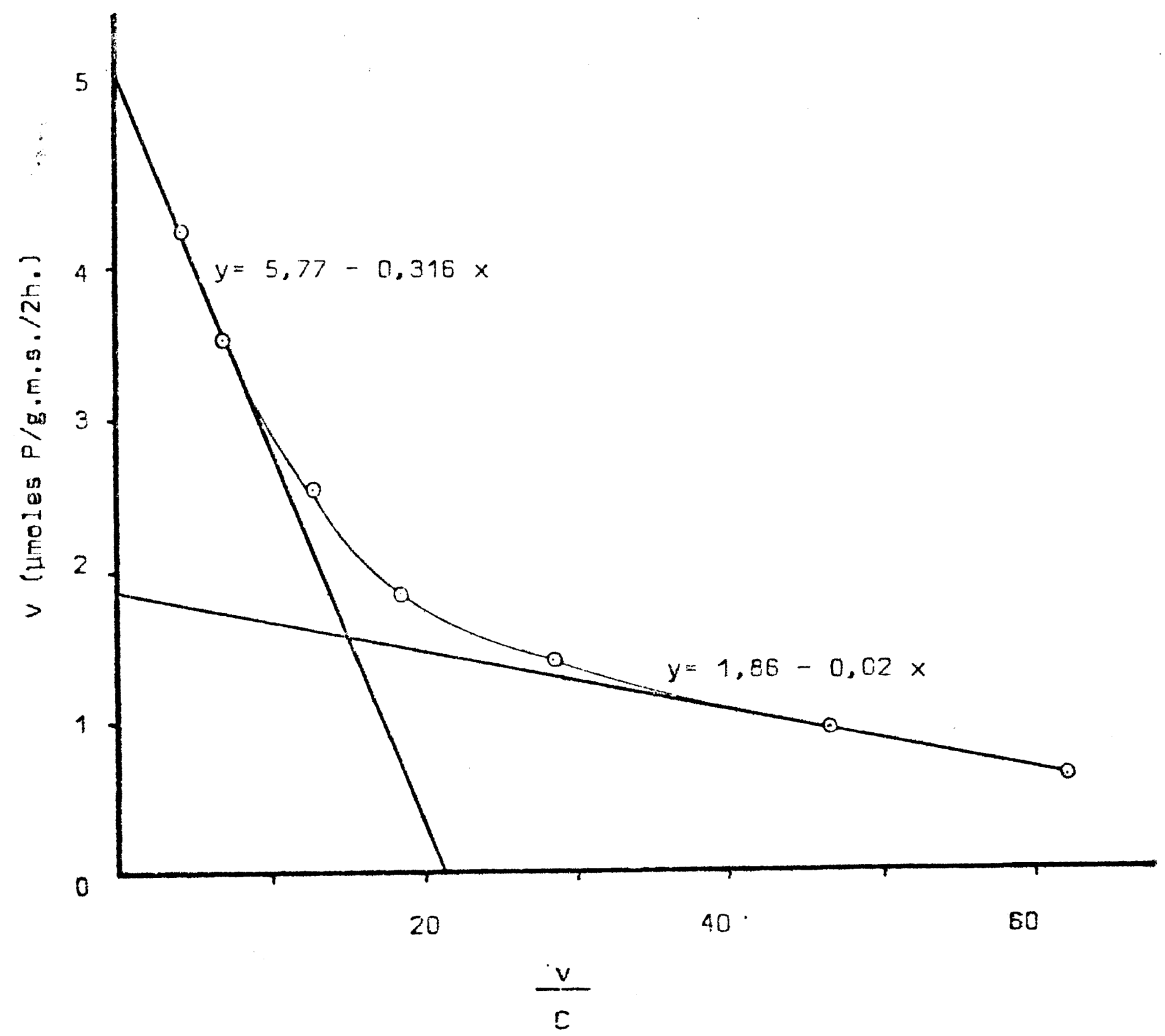

Figura 6 - Transformada de Hofstee. Absorção de $\mathrm{P}$ por raízes destacadas de sorgo. Média das três variedades em função da concentração externa. Tempo de contato: 2 horas.

mente pelas Fig. 5 e 6 que a transformada de Hofstee se presta melhor distribuição ao longo da curva. Por essa razão foi a transformada adotada na interpretação dos dados. Utilizando-se do processo descrito anteriormente decompôs-se a curva da Fig. 6 em dois segmentos, obtendo-se os seguintes valores médios das três variedades; para baixas concentrações: $\mathrm{K}_{\mathrm{m}}=0,02$ umoles $/ \mathrm{ml} \mathrm{e} \mathrm{V}_{\max }=1,86$ umoles $/ \mathrm{g} . \mathrm{m} . \mathrm{s} .2$ h. para altas concentrações: $\mathrm{K}_{\mathrm{m}}=0,316$ umoles $/ \mathrm{ml} \mathrm{e} \mathrm{V}_{\max }=5,77$ umoles/g.m.s. 2 horas.

Passando-se a analisar variedade por variedade, as figuras 7,8 e 9 representam graficamente os dados obtidos segundo a transformada de Hofstee, para as variedades CBr-102, DeKalb, Tey-101 respectiva- 
mente. Os valores de $\mathrm{K}_{m}$ e $\mathrm{V}_{\max }$ obtidos estão presentes na Tabela 3 . Incluiu-se também nesta tabela os valores de $\mathrm{v}$ e $\mathrm{V}$ do ponto de intersecção das retas, ou seja, o ponto de transição entre os mecanismos de absorção .

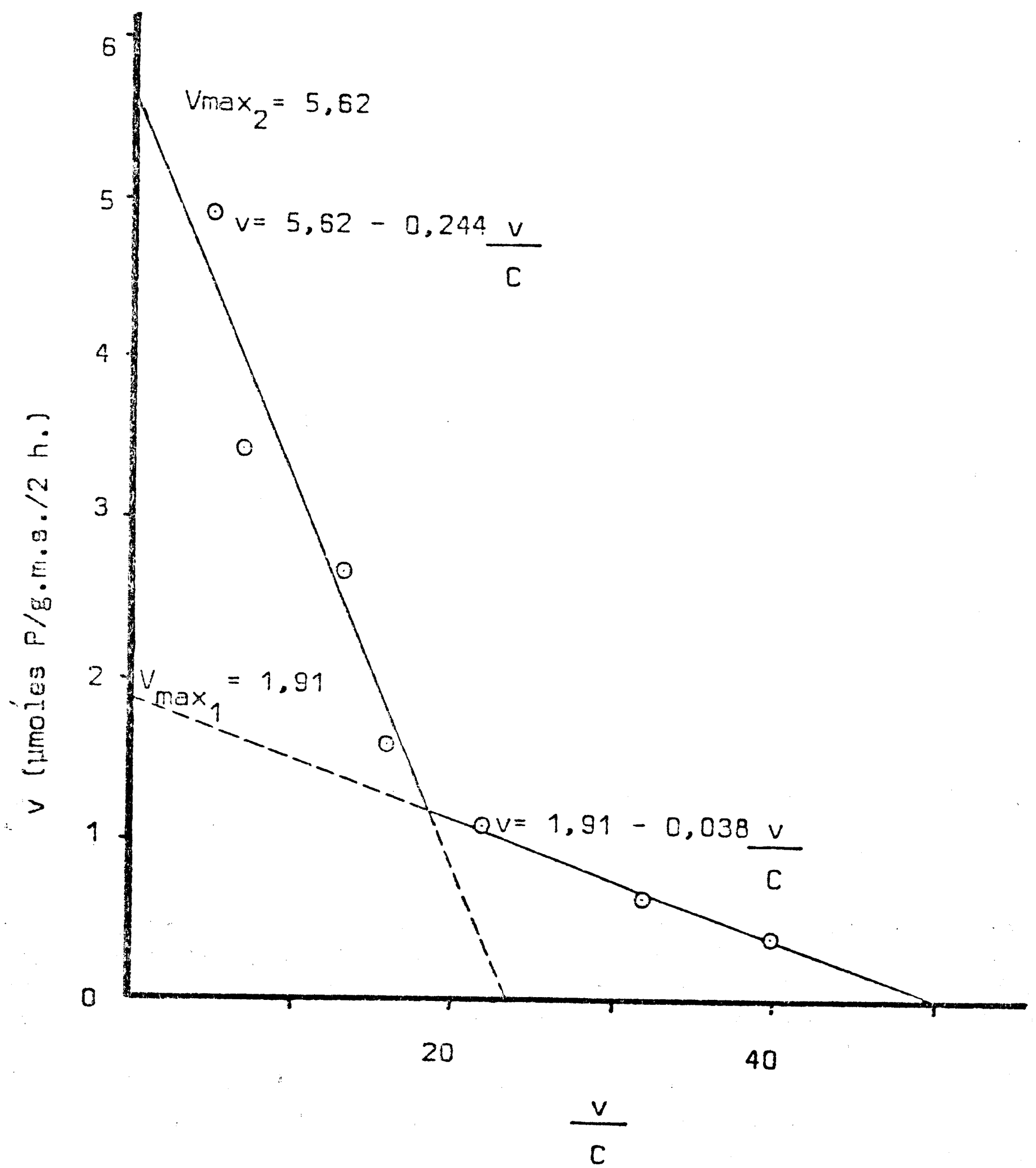

Figura 7 - Transformada de Hofstee para a variedade CBr-102. Absorção de $\mathrm{P}$ por raízes destacadas de sorgo em função da concentração externa. Tempo de contato: 2 horas. 


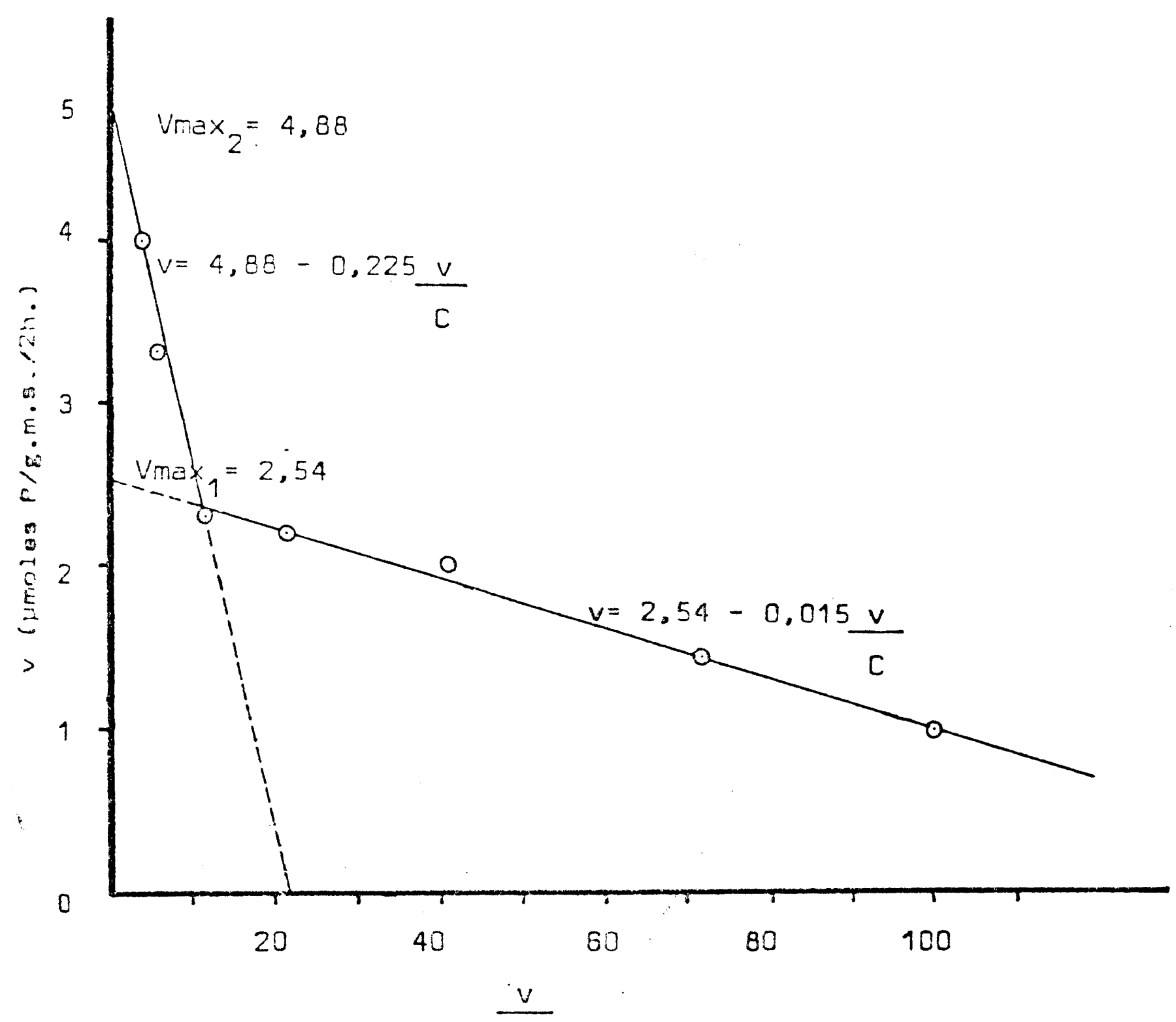

Figura 8 - Transformada de Hofstee para a variedade Dekalb. Absorção de $\mathrm{P}$ por raízes destacadas de sorgo em função da concentração externa. Tempo de contato: 2 horas. 


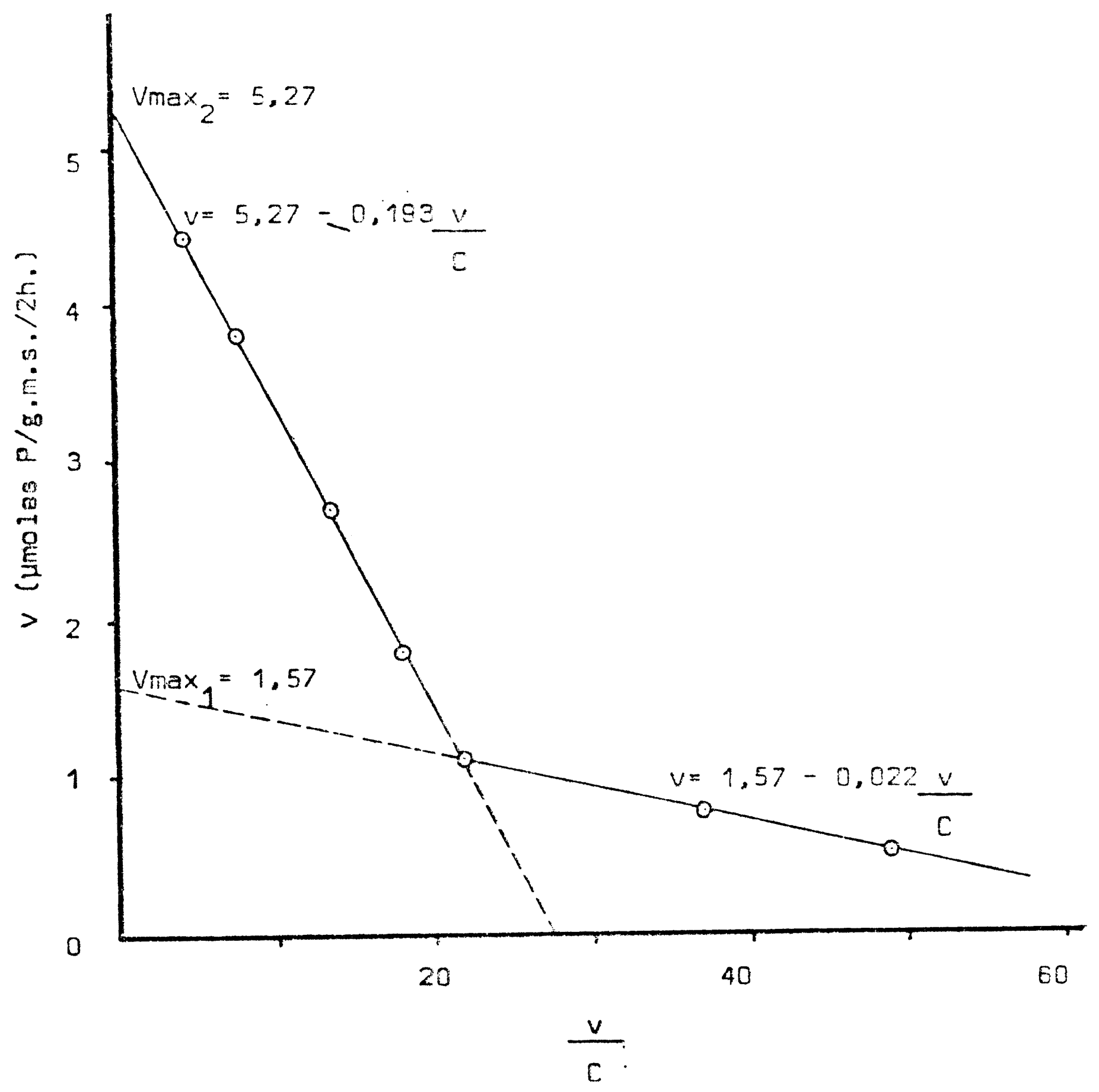

Figura 9 - Transformala de Hofstce para a variedade Tey-101. Absorção de P por raízes destacadas de sorgo em função da concentração externa. Tempo de contato: 2 horas. 
TABELA 3 - Valores de $\mathrm{K}^{m}$ e Vmax para altas e baixas concentraçxes e valores de $\mathrm{v}$ e $\mathrm{C}$ do ponto de intersecção das retas na transformada de Hofstee

\begin{tabular}{lccccccc}
\hline Variedades & \multicolumn{2}{c}{ baixas concentraç. } & \multicolumn{2}{c}{ altas concentraç. } & ponto de transição \\
\hline & $\begin{array}{c}\mathrm{K} \text { ml } \\
\mathfrak{u} / \mathrm{moles} / \mathrm{ml}\end{array}$ & $\mathrm{V}^{\max _{1}}$ & $\mathrm{~K} \mathrm{~K}_{\mathfrak{2}}$ & $V_{\text {max }}{ }_{2}$ & $\mathrm{C}$ & $\mathrm{V}$ \\
\hline $\mathrm{CBr}$ & 0,038 & 1,904 & 0,244 & 5,616 & 0,07 & 1,205 \\
DeKalb & 0,015 & 2,536 & 0,225 & 4,88 & 0,21 & 2,36 \\
Tey & 0,022 & 1,568 & 0,193 & 5,271 & 0,05 & 1,096 \\
\hline
\end{tabular}

Como consta na Tabela 3, as variedades C.Br.102 e Tey-101 se apresentaram como um comportamento semelhante na primeira fase do mecanismo duplo de absorção iônica, com uma velocidade de absorção maior $\left(\mathrm{Km}_{1}\right.$ menor) do que a variedade DeKalb, porém, com uma velocidade máxima menor em relação à DeKalb. A transição entre os mecanismos para a variedade $\mathrm{CBr} .102$ e Tey-101 ocorre numa concentração da solução externa em torno de 0,06 umoles $/ \mathrm{ml}$, enquanto que na DeKalb, a concentração é cerca de 3 a 4 vezes maior $(0,21$ umoles/ $\mathrm{ml}$ ). Os valores de velocidade de absorção para o ponto de transição é cerca de 1,1 umoles $/$ g.m.s. $/ 2$ horas, para as variedades CBR-102 e Tey-101 e para a variedade DeKalb cerca de 2 vezes maior (2,36 umoles/g.m.s. $/ 2$ h. Quando a segunda fase do mecanismo duplo de absorção iônica, as variedades CBr-102 e Tey-101 se apresentaram com $\mathbf{V}_{\max }$ maior que a variedade DeKalb.

A variedade DeKalb apresentou uma resposta de absorção maior, em relação às outras duas até uma concentração em torno de 0,15 umo$\mathrm{les} / \mathrm{ml}$. Posteriormente de 0,15 a $1 \mathrm{umol} / \mathrm{ml}$, as variedades $\mathbf{C B r}-102 \mathrm{e}$ Tey-101 apresentaram maiores respostas de absorção de $\mathbf{P}$ com 0 aumento da concentração externa, como se observa na Figura 3 .

4.3. Absorção de $P$ em função da temperatura

A absorção iônica pelas células do vegtal é um processo irreversível e altamente dependente do metabolismo. A temperatura ideal para um bom desenvolvimento vegetal está ao redor de $30^{\circ} \mathrm{C}$ (MALAVOLTA, 1970), na qual a atividade metabólica da célula seria maximizada. A $\mathrm{O}^{\circ} \mathrm{C}$ a atividade metabólica sofreria uma interrupção.

Considerando $A_{0}$ e $A_{30}$ as quantidades de fósforo absorvidas a $D$ e $30^{\circ} \mathrm{C}$ respectivamente, $A_{0}$ seria a quantidade absorvida por simples difusão enquanto que $A_{: 0}$ seria a quantidade absorvida por processos ativos somada do valor de $A_{0}$.

Supondo-se essa premissa verdadeira, a relação entre os processos ativos e passivos de absorção seria dado por:

$$
\mathbf{Q}=\frac{\mathbf{A}_{\mathbf{3 0}}-\mathbf{A}_{\mathbf{0}}}{\mathbf{A}_{0}}
$$


Os dados obtidos estão presentes na Tabela 4 bem como os valores de $\mathbf{Q}$.

TABFI $\Lambda 4$ - Valores de absorção $\mathrm{P}$ por raizes destacadas de sorgo e 0 e $30^{\circ} \mathrm{C}$, durante 2 horas. Concentração da solução externa 0,1 umoles/ml

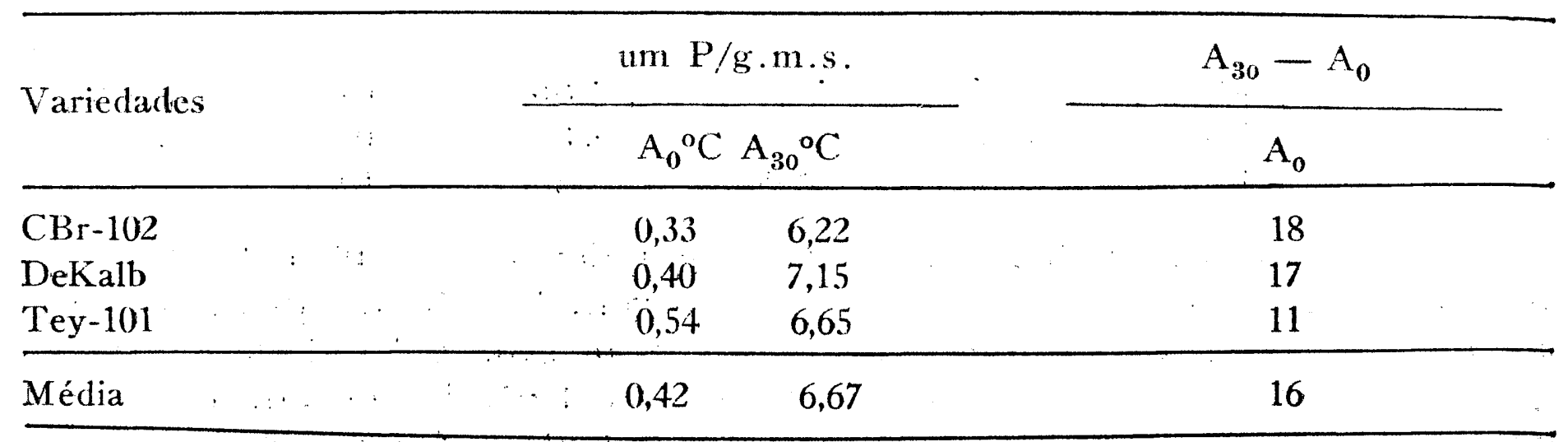

Como se verifica pela Tabela 4 a absorção de fósforo por raízes destacadas de sorgo é altamente dependente da temperatura e conseqüentemente do metabolismo celular. A temperatura de $30^{\circ} \mathrm{C}$ a absorção de $\mathrm{P}$ foi cerca de 16 vezes maior que a $\mathrm{O}^{\circ} \mathrm{C}$, para um período de tempo de 2 horas, sugerindo que a relação entre a quantidade de $P$ absorvida àtivamente e a difundida no apoplasto passivamente esteja nessa ordem de grandeza.

\subsection{Absorção de fósforo em função do $\mathrm{pH}$}

O pH médio ideal para o desenvolvimento de plantas no solo está em torno de 6,5 (MALAVOLTA et al., 1974).

Os elementos passíveis de serem absorvidos pela planta estão envolvidos em reações entre o solo (fase sólida), a solução do solo e a própria planta. Portanto, quando se diz que o pH ideal para a planta está em tơnno de 6,5 isso não significa que nesse pH e planta encontre melhores condições para absorver ions de uma soluçã̃o. Nem tampouco que nesse $\mathrm{pH}$ o solo coloque em solução uma quantidade de ions, bem como uma relação entre eles ideal para o desenvolvimento da planta. Eim, o conjunto desses fatores que estabelece o pH ideal para uma dada cultura.

O presente trabalho tem por finalidade estudar a variação da absorção do fósforo a dois valores de $\mathrm{pH}$ eliminando a interferência do solo no sistema. A Tabela 5 contém os valores de absorção obtidos.

Segundo análise estatística (teste t) não houve diferença significativa entre as médias à pH 3 e 6 . Esse resultado sugere que os problemas de absorção de $\mathbf{P}$ estariam relacionados mais com o solo do que com a própria planta (disponibilidade dependente do $\mathrm{pH}$ ) . 
TABELA 5 - Valores de absorção de fósforo por raizes destacadas de sorgo a pH 3 e 6.

\begin{tabular}{|c|c|c|}
\hline Variedades & $\mathrm{pH}_{3}$ & $\mathrm{pH}_{6}$ \\
\hline $\mathrm{CBr}-102$ & 9,38 & 10,82 \\
\hline DeKalb & 10,77 & 9,85 \\
\hline Tey-101 & 10,66 & 12,11 \\
\hline Média & 10,27 & 10,93 \\
\hline
\end{tabular}

4.5. Influência da aeração e inibidores respiratórios na absorção de fósforo

A Tabela 6 apresenta os dados de absorção de fósforo em função do arejamento e presença de inibidores respiratórios. Como se observa melhor na representação gráfica dessa tabela (Fig. 10), os tratamentos com $\mathrm{CN}$-, inibidor da cadeia de transporte eletrônico terminal e 2,4 DNP desacoplador da fosforilação oxidativa apresentaram em geral acentuada inibição da absorção de $\mathrm{P}$ pelas raízes destacadas em relação à testemunha com arejamento; não ocorre o mesmo nos tratamentos com ausência de arejamento e presença de F-, inibidor de glicólise os quais não provocaram alteraçỗes significativas em relação à testemunha. Essas comprovações puderam ser obtidas através do tesde Tukey ao nível de $5 \%$.

O efeito do CN- e 2,4 DNP está de acordo com BUTLER (1953), JAMES (1953) e HOPKINS (1956). No caso do tratamento sem arejamento, levando-se em conta as afirmações de HOPKINS (1956) nota-se que a quantidade de $\mathrm{O}_{2}$ em solução deve ser superior a $3 \%$, pois a absorção de fosfato não é afetada na faixa de 3 a $100 \%$.

TABELA 6 - Dados de absorção de fósforo em função do arejamento e inibidores respiratórios

\begin{tabular}{lccccc}
\hline \multirow{2}{*}{ Variedades } & \multicolumn{4}{c}{ u moles $\mathrm{P} / \mathrm{g} \cdot \mathrm{m} . \mathrm{s}}$. \\
& testemunha & -Ar & F- & CN- & 2,4 DNP \\
\hline CBr-102 & 2,13 & 2,99 & 3,39 & 0,50 & 1,09 \\
DeKalb & 3,79 & 3,77 & 2,97 & 0,58 & 1,84 \\
Tey-101 & 4,29 & 3,40 & 3,26 & 0,65 & 1,54 \\
Média & 3,40 & 3,39 & 3,21 & 0,58 & 1,49 \\
\hline
\end{tabular}




\section{RESUMO E CONCLUSÕES}

Foram realizados diversos experimentos com a finalidade de estudar a influência do tempo, concentração externa, $\mathrm{pH}$, temperatura, aeração e inibidores (KF, KCN e 2,4-DNP) sobre a absorção de fosfato por raízes destacadas de sorgo granífero, Sorghum bicolor L. Moench, var. Contibrasil-102, DeKalb e Tey-101, utilizando-se o $\mathrm{H}_{3}{ }^{32} \mathrm{PO}_{4}$ como traçador.

Pode-se concluir que:

a. No intervalo de tempo estudado, a velocidade de absorção de P da variedade Tey-101 foi menor que as demais.

b. Todas as variedades se apresentaram com mecanismo duplo de absorção. Em baixas concentrações a variedade DeKalb apresentou resposta de absorção maior que as demais, ocorrendo o contrário em altas concentrações.

c. A absorção não foi influenciada pela variação do $\mathrm{pH}$.

d. Aumento de absorção foi propiciado pelo aumento de temperatura.

e. Os tratamentos CN e 2,4 DNP diminuíram a absorção, enquanto que sem aeração e F- não tiveram influência.

\section{SUMMARY}

STUDIES ON THE MINERAL NUTRITION OF GRAIN SORGHUM. VI ABSORPITION OF PHOSPHATE BY EXCISED ROOTS OF THREE COMMERCIAL VARIETIES

-... Experiments were carried out in order to study the effect of time external concentration, $\mathrm{pH}$, temperature, acration and inhibitors ( $\mathrm{KF}, \mathrm{KCN}$ and 2,4-DNP) on the phosphate absorption by the excised roots of grain Sorghum bicolor L. Moench var. Contibrasil 102, DeKalb and Tey-101, using ${ }^{32} \mathrm{P}$ as tracer. It was concluded that:

a. In the time interval studied, the velocity of $\mathrm{P}$ absorption was lower in the $T(y-101$ variety than the other varieties.

b. All of the varieties showed double absorption mechanism. When low P concentrations were used, the DeKalb var'ety showed a higher absorption rate in relation to the other varieties, occurring the opposite as the concentration increased.

c. There was no change on the absorption as result of $\mathrm{pH}$ variation from 3,0 to 6,0

d. By increasing the temperature, a higher absorption rate was observed.

e. There was a decrease on the absorption rate with the CN- and 2,4-DNP treatments, and no influence of aeration and F-. 


\section{LITERATURA CITADA}

BUTLER, G.W., 1953. Ion uptake by young wheat plants. III. Phosphate absorption by excised roots. In: Physiologia Plantarum. Copenhagen. Amsterdam. Ed. Scandinavica 6: 637-661.

EPSTEIN, E. 1975. Nutrição Mineral de Plantas. Rio de Janeiro, Livros Técnicos e Cieníficos S.A. Tradução de E. Malavolta, 341 p.

HAGEN, C.E. \& H.T. HOPKINS. 1955. Ionic species in orthophosphate absorption by barley roots. Plant Physiol. Washington, USA 30: 193-199.

HOAGLAND, D.R. \& D.I. ARNON. 1950. The water culture method for growing plants without soil. Calif. Agr. Exp. Sta. Circ. 347.

HOFSTEE, B.H.J. 1952. On the evoluation of the constants $\mathrm{Vm}$ and $\mathrm{Km}$ in enzyme reactions. Science Washington, USA, 116:329-331.

HOPKINS, H.T. 1956. Absorption of ionic species of othophosphate by barley roots: effects of 2,4 dinitrophenol and oxigen tension. Plant Physiology, Washington, U.S.A. 31(2): 155-161.

HUMBERT, R.P. 1968. The Growing of Sugar Cane. Amsterdam. Elsevier Pyblishing Company, $779 \mathrm{p}$.

JACKON, S.B., S.B. HENDRICKS \& B.M. VASTA. 1962. Phosphorylation by barley root mitocondria \& phosphate absorption by barley roots, Plant Physiology. Washington, U.S.A. 37(15): 8-17.

JAMES, W.O. 1953. The use of respiratory inhibitors. Annual review of plant physiology. Standord, California, U.S.A. 4: 59-90.

KNOLI, H.A. D.J. LATHWELL \& N.C. BRADY. 1964. The influence of root zone temperature on the growth and cpatents of phosphorus and anthocyanin. Soil Sci. Soc. Amer. Proc. Madison, Wisconsin 28(3): 400-403.

LINGLE, J.C. \& R.M. DAVIS. 1959. The influence of soil temperature and phospharus fertilization on the growth and mineral absorption of tomato seedlings. Proc. Amer. Soc. Hort. Sci., Ithaca. New York. $73: 312-322$.

LOUGHMAN, B.C. \& R.S. RUSSELL, 1957. The absorption and utilization of phosphate by young barley plants. Journal of Experimental Botany. Oxford, England, 8(23): 28()-293.

MAL.AVOLTA, E. 1976. Manual de Química Agrícola. São Paulo, Editora Agronômica Ceres. 528 p.

MALAVOLTA, E. 1970. Nutrição Mineral de Plantas. Curso Pós Graduado de Solos e Nutrição de Plantas. Piracicaba, São Paulo, ESALQ 234 p. (nimeografado)

MCNLLTY, I.B. \& J.L. LORDS. 1960. Possible explanation of fluoride-idduced respiration in Chlorella purenoidosa. Scierce, Washington U.S.A. 132(3439): 1553-1554.

NIELSEN, K.F.; R.L. HALSTEAD; A.J. MACIEN, S.I. BOURGET \& R.M. HOLMES. 1961. The influence of soil temperature on the growth and mineral composition of corn, bromegrass and potatos. Soil Sci. Soc. of An. Proc. Madison, Wisconsin 26: 369-372.

NISSFN, P. 1973. Multiphasic Uptake in plants. I. Phosphate and sulphate. Plant Pinysiol. Washington U.S.A. 28-304-316.

NOCGI.E, J.C. \& M.FRIED, 1960. A kinetic analysis of phosphate absorption by excised roots of millet, bariey and alfafa. Soll Sic. Soc. Amer. Proc. Madison, Wisconsin. 24(1):33-35.

PHILLIPS, J.W., D.E. EAKER \& C.O. Cl.AGETT, 1971. Kinctes of P absorption by excised roots and leaves of corn hybrids. Agronomy Journal, Madison. Wisconsin, 63(4): 517-520. 
